\title{
Prevalence and Characterization of Listeria Species from Raw Milk and Dairy Products from Çanakkale Province
}

\author{
Pınar Şanlıbaba $^{1^{*}}$, Başar Uymaz Tezel ${ }^{2}$ \\ ${ }^{I}$ Department of Food Engineering, Ankara University Engineering Faculty, 06830 Gölbaşı/Ankara, Turkey \\ ${ }^{2}$ Food Technology Program, Bayramiç Vocational School, Çanakkale Onsekiz Mart University, 17700 Bayramiç/Çanakkale, Turkey
}

\section{A R T I C LE IN F O}

\section{Research Article}

Received 11 October 2017 Accepted 02 December 2017

Keywords:

Listeria specie

Raw milk

Dairy products

Identification

Characterization

E-mail: sanlibab@ankara.edu.tr

\begin{abstract}
A B S T R A C T
The objective of this study was to determine the prevalence of Listeria species, specifically Listeria monocytogenes, in raw milk, pasteurized milk, white cheese, and homemade cheese. A total of 200 food samples were collected and analyzed to examine the presence of Listeria spp. The EN ISO 11290-1 method was used for isolation of Listeria. API Listeria test kit was used for biochemically characterization. Listeria spp. were isolated in 25 of the 200 samples (12.5\%). The largest number of Listeria spp. was detected in homemade cheese $(24 \%)$, followed by raw milk $(18 \%)$, and white cheese $(8 \%)$. Listeria spp. were not isolated from the pasteurized milk. The most common species isolated were Listeria innocua (5.5\%); the remaining Listeria isolates were Listeria ivanovi (3.5\%), Listeria welshimeri (3\%), and Listeria monocytogenes $(0.5 \%)$. Listeria monocytogenes was detected in only raw milk.
\end{abstract}

DOI: https://doi.org/10.24925/turjaf.v6i1.61-64.1641

\section{Introduction}

Listeria spp. are Gram positive, and facultative anaerobic organisms. They are also non-spore forming, and rod-shaped bacteria (Momtaz and Yadollahi, 2013; Odetokun and Adetunji, 2017). The genus Listeria has been divided so far into 17 species and 4 subtypes on the basis of 16S rRNA sequences (Anon., 2017). L. monocytogenes, $L$. seeligeri, $L$. ivanovii, $L$. welshimeri, $L$. innocua, $L$. grayi can be isolated from foods. These strains referred to as "classic" Listeria spp. Recently, 11 new species of the genus Listeria were identified. These are: L. marthii, $L$. fleischmannii, $L$. floridensis, $L$. aquatica, L. newyorkensis, L. cornellensis, L. rocourtiae, $L$. weihenstephanensis, $L$. grandensis, $L$. riparia and $L$. booriae. These newly identified species were isolated from foods and other environmental niches around the world (Barre et al., 2016). L. monocytogenes and $L$. ivanovii are the two known pathogenic species within this genus. Although L. monocytogenes may lead to illness and death in humans and other mammals, L. ivanovii is primarily associated with ruminant animals (Hellberg et al., 2013). L. monocytogenes is the principle reason of listeriosis. It is transmitted to infect the susceptible individuals via consumption of the contaminated foods. The major risk population groups at risk for invasive listeriosis are the immunocompromised hosts such as pregnant women, unborn or newly delivered infants, organ transplant recipients, cancer and AIDS patients, and the elderly, with fatality rates of 20-30\% (Jamali et al., 2013; Yehia et al., 2016; Phraephaisarn et al., 2017). Listeria species are widely distributed in many different environments. These environments are soil, surface water, sewage, animal feed, farm environments, food processing equipments and environments, urban and suburban settlements (Korsak and Szuplewska, 2016). In addition, this species can be found in a wide variety of raw and processed foods. These foods are milk and dairy products, various meats and meat products such as beef, fermented sausages, fish products, ready-to-eat foods, and vegetables. These contaminated foods have been implicated in several outbreaks of human listeriosis (Saludes et al., 2015). 
Listeria spp. are the most frequently prevalent in the milk processing environment. Although pasteurization process destroys L. monocytogenes in raw milk, this process does not eliminate later risk of contamination of dairy products. Also, dairy products may become contaminated with L. monocytogenes during subsequent stages of production (Seyoum et al., 2015). The aim of the present work was to provide information about Listeria spp. strains isolated from raw milk and dairy products produced in Çanakkale (Turkey), focusing on their prevalence, phenotypic and biochemical characteristics.

\section{Materials and Methods}

\section{Sampling}

Between October 2016 and February 2017, a total of 200 food samples including raw milk, pasteurized milk, white cheese and homemade cheese were randomly purchased from various local bazaars and supermarkets in Çanakkale, Turkey. The samples were transported to the laboratory under cold conditions on the sampling day and processed immediately.

\section{Bacterial Strains and Culturing}

Listerial strains isolated in this study and the references strains were propagated on Brain Hearth Infusion (BHI) Broth (Merck, Germany) and Tryptone Soy Broth supplemented with $0.6 \%$ of yeast extract (TSBYE) (Sigma, Germany). They were grown at $35^{\circ} \mathrm{C}$ for 24 h. The initial isolates of strains were stored at $-20^{\circ} \mathrm{C}$ with $30 \%$ (v/v) glycerol (Merck, Germany).

The standard strain of L. monocytogenes ATCC 7644 was obtained from the culture collection of Prokaryote Genetics Laboratory, Department of Biology, Faculty of Science, Ankara University, Ankara, Turkey.

\section{Isolation and Identification of Listeria}

Listeria spp. were isolated from raw milk and dairy products according to the International Organization for Standardization (ISO 11290-1) procedure as described by Garedew et al., (2015). Two-step method for enrichment of Listeria spp. was performed in accordance with the standard. Twenty five grams of cheeses were added to $225 \mathrm{ml}$ of $1 / 2$ Fraser broth (Merck, Germany) as the first selective enrichment medium. It was homogenized in a stomacher-400 (London, UK) at high speed for two minutes and incubated for $24 \pm 2 \mathrm{~h}$ at $30 \pm 1^{\circ} \mathrm{C}$. Similarly, $25 \mathrm{ml}$ milk was sampled and $\mathrm{pH}$ adjusted to neutral and thoroughly mixed with $1: 10$ ratio to $1 / 2$ Fraser broth and incubated at $30 \pm 1^{\circ} \mathrm{C}$ for $24 \mathrm{~h}$. After first enrichment step, $0.1 \mathrm{ml}$ of $1 / 2$ Fraser broth culture was transferred to $10 \mathrm{ml}$ of Fraser broth as a secondary enrichment medium and incubated at $37^{\circ} \mathrm{C}$ for $48 \pm 2 \mathrm{~h}$. At the same time, after primary enrichment incubation, a loop full of culture was streaked onto ALOA (Agar Listeria Ottaiani Agosti) agar (Merck, Germany) and PALCAM (Polmixin Acriflavin Lithium Chloride Ceftazidime Aesculin Mannitol) agar (Merck, Germany) and incubated for $24-48 \mathrm{~h}$ at $37^{\circ} \mathrm{C}$. After incubation, a loopful of secondary enrichment culture was streaked onto ALOA and PALCAM agar plates and incubated, at $37^{\circ} \mathrm{C}$ for $24-48 \mathrm{~h}$. It was observed that grey-green colonies with black background on PALCAM agar plates, which is typical for Listeria spp.
Typical green-blue colored colonies with/without distinctive opaque colonies were determined on ALOA agar. Three to five presumptive colonies from ALOA and PALCAM agar were re-streaked on Tryptone Soy Agar supplemented with $0.6 \%$ of yeast extract (TSA-YE) (Sigma, Germany) at $37^{\circ} \mathrm{C}$ for $24-48 \mathrm{~h}$. Typical colonies from TSA-YE (1 $\mathrm{mm}$ to $2 \mathrm{~mm}$ in diameter, convex, colourless and opaque) were subjected to standard biochemical tests including Gram staining, catalase activity, oxidase activity, and stabbed into a motility medium at $25^{\circ} \mathrm{C}$ and $35^{\circ} \mathrm{C}$ for observing the characteristics umbrella motility. The isolated and characterized strains were identified using API Listeria test system according to the manufacturer recommendations (BioMeriux, France). The reference strain L. monocytogenes ATCC 7644 was used in all biochemical tests.

\section{Results}

A total of 200 food samples were analyzed for possible contamination with Listeria spp. according to ISO 11290-1 method, which is based on biochemical identification of suspected colonies on ALOA and PALCAM agar plates. Twenty five samples (12.5\%) were found to be positive for Listeria spp. A total of 25 isolates were found to be Gram positive, catalase positive, oxidase negative, and the characteristics umbrella motility into a motility medium. All of the 25 isolates were also biochemically determined at species level using the API Listeria (data not shown). The incidence of $L$. monocytogenes and other Listeria spp. from raw milk and dairy products was given in Table 1 . The counts of Listeria spp. was distributed as follows: $0.5 \%$ (1 of 200) to L. monocytogenes, $5.5 \%$ (11 of 200) to L. innocua, $3.5 \%$ (7 of 200) to L. ivanovii, and 3\% (6 of 200) to $L$. welshimeri. None of the other Listeria species were determined. The highest prevalence of Listeria spp. was detected in homemade cheese $(24 \%, 12$ of 50), followed by raw milk $(18 \%, 9$ of 50$)$, and white cheese $(8 \%, 4$ of 50).

The isolates L. innocua (8\%, 4 of 50), L. ivanovi (6\%, 3 of 50), L. monocytogenes (2\%, 1 of 50) and $L$. welshimeri $(2 \%, 1$ of 50$)$ were observed in raw milk. $L$. monocytogenes was detected in only raw milk $(0.5 \%, 1$ of 200). The most common species isolated in homemade cheese was L. innocua (10\%, 5 of 50); the remaining Listeria isolates were L. welshimeri (8\%, 4 of 50), and L. ivanovi $(6 \%, 3$ of 50). In white cheese, L. innocua $(4 \%, 2$ of 50), L. welshimeri (2\%, 1 of 50), and L. ivanovi (2\%, 1 of 50) were also detected. Listeria spp. was not isolated from the pasteurized milk.

\section{Discussion}

In this study, Listeria spp. were isolated from $12.5 \%$ (25 of 200) raw milk and dairy products. L. innocua was known to be the highest prevalent Listeria spp. (Gebretsadik et al., 2011). In the present study, the dominant Listeria spp. isolated was L. innocua $(5.5 \%)$. This finding was in agreement with earlier report (Abrahao et al., 2008; Gebretsadik et al., 2011; Rahimi et al., 2012; Jamali et al., 2013). 
Table 1 Incidence of $L$. monocytogenes and other Listeria spp. in raw milk and dairy products

\begin{tabular}{|c|c|c|c|c|c|c|}
\hline \multirow{2}{*}{ Nature of Samples } & \multirow{2}{*}{$\begin{array}{c}\text { Number of } \\
\text { Samples }\end{array}$} & \multicolumn{4}{|c|}{ Number (\%) of Positive Samples } & \multirow{2}{*}{ Total $(\%)$} \\
\hline & & L. monocytogenes & L. innocua & L. ivanovii & L. welshimeri & \\
\hline Raw Milk & 50 & $1(2 \%)$ & $4(8 \%)$ & $3(6 \%)$ & $1(2 \%)$ & $9(18 \%)$ \\
\hline Pasteurized Milk & 50 & - & - & - & - & - \\
\hline White Cheese & 50 & - & $2(4 \%)$ & $1(2 \%)$ & $1(2 \%)$ & $4(8 \%)$ \\
\hline Homemade Cheese & 50 & - & $5(10 \%)$ & $3(6 \%)$ & $4(8 \%)$ & $12(24 \%)$ \\
\hline Total & 200 & $1(0.5 \%)$ & $11(5.5 \%)$ & $7(3.5 \%)$ & $6(3 \%)$ & $25(12.5 \%)^{\mathrm{a}}$ \\
\hline
\end{tabular}

Calculated for total of 200 samples

L. monocytogenes was isolated from only raw milk $(0.5 \%)$ in this study. Our findings were noticed that the frequency of isolation of L. monocytogenes was much lower. This observation also agrees with that of VardarÜnlü et al., (1998), Sağun et al., (2001), Aygun and Pehlivanlar, (2006), Taşçı et al., (2010), Abay et al., (2012), and Durmaz et al., (2015), who found 4\% in Sivas, $1.2 \%$ in Van, $0 \%$ in Antakya, $2.4 \%$ in Burdur, $0 \%$ in Kayseri, and $2.2 \%$ in Şanlıurfa and Adıyaman, respectively. In other countries, as opposed to our study, the reported isolation rates of L. monocytogenes from raw milk samples were $16.7 \%$ in Brazil (Silva et al., 2003), $6.5 \%$ in United States (van Kessel et al., 2004), 4\% in Iran (Jami et al., 2010), 22\% in Ethiopia (Gebretsadik et al., 2011), 6.3\% in Ireland (Fox et al., 2011), 41.6\% in Syria (Al-Mariri et al., 2013), 21.7\% in Malaysia (Jamali et al., 2013), and $16.6 \%$ in India (Nayak et al., 2015). Contamination rates of $L$. monocytogenes are affected seasonal variations (Taşçı et al., 2010). Samplings in our study were collected between October 2016 and February 2017. The low prevalence of $L$. monocytogenes in raw milk may be the result of seasonal factor. In this study, $L$. innocua was the main Listeria spp. isolated from raw milk which is agreement with earlier findings reported by Silva et al., (2003); Rahimi et al., (2012); Jamali et al., (2013), and Seyoum et al., (2015). Infected animals, poor silage quality, insufficient hygiene, and environmental condition which could occur during milking and storage are likely the most common causes of $L$. monocytogenes in raw milk. Listeria spp. were not detected from pasteurized milk. Similar results were reported by VardarÜnlü et al., (1998) and Sarker and Ahmed (2015). In contrast to our findings, Silva et al., (2003) detected Listeria spp. in pasteurized milk (16.7\%). Thermal process like pasteurization does not in any way guarantee the absolute safety of milk and dairy products.

Among the samples tested in this study, homemade cheese had the highest percentage rate of Listeria spp. (24\%), particularly L. innocua (10\%), L. welshimeri (8\%), and L. ivanovii (6\%). Overall, 4 listerial strains were isolated from White cheese analyzed in this study, of which $2(4 \%)$ were $L$. innocua, and $1(2 \%)$ was $L$. welshimeri and the remaining $1(2 \%)$ was $L$. ivanovii. $L$. monocytogenes was not detected from these sources in agreement with Demir and Öksüztepe, (2016). In contrast, contrary results were noted by some researchers. Arslan and Özdemir, (2008) detected L. monocytogenes in $9.2 \%$ cheese samples. Furthermore, Kaptan (2016) was determined L. monocytogenes in $15.77 \%$ of cheese samples. In other countries, as similar to our study, the reported isolation rates of $L$. monocytogenes from cheese samples were 0\% in Algeria (Bouayad et al., 2012), and Iran (Shamloo et al., 2015). In contrast to the present study, a high percentage of $L$. monocytogenes contamination to cheese samples was obtained: $6.7 \%$ in Brazil (Abrahao et al., 2008) and 9.8\% in Spain (Arrese and Arroyo-Izaga, 2012). The contamination reasons of $L$. monocytogenes in fermented milk products were: i) Insufficient heat treatment of milk to kill the organisms, ii) the resistance of Listeria to the decreased $\mathrm{pH}$ during cheese production, and iii) cross contamination through air, soil, equipment and processing units staff (Bouayad et al., 2012).

A total of 100 cheese samples (homemade and white cheese), $16 \%$ (16 of 100) were positive for Listeria spp. in this study. In other reports conducted with cheese in Turkey, isolation rates of Listeria spp. was 33.1\% (Arslan and Özdemir, 2008) and 100\% (Kaptan, 2016). These results mentioned above were higher than our findings. In contrast, a lower incidence of Listeria spp. was found by Aygun and Pehlivanlar, (2006). In countries other than Turkey, as similar to our study, the prevalence of Listeria spp. in cheese samples was reported as $16.7 \%$ in Brazil (Silva et al., 2003), 12.2\% in Brazil (Abrahao et al., 2008), $15 \%$ in Iran (Rahimi et al., 2012), and $10 \%$ in Egypt (Elshinaway et al., 2017). L. ivanovii is connected with listeriosis. Because of this, the presence of $L$. ivanovii in cheese samples is concerned. In this study, a higher frequency of $L$. ivanovii in homemade cheese than white cheese was observed.

\section{Conclusions}

Outbreaks of listeriosis, caused by consumption of milk and dairy products indicate the danger to consumer health. We isolated the Listeria species from raw milk and dairy products and identified by API Listeria STREP. The results of this study provide information about the contamination status of raw milk and dairy products in Çanakkale with Listeria spp. The highest prevalence of Listeria spp. was detected in homemade cheese followed by raw milk, and White cheese. The most common species was $L$. .innocua, the remaining Listeria isolates were L. ivanovi, L. welshimeri and L. monocytogenes. Considering of the low frequency of L. monocytogenes in this study, raw milk cannot be omitted as a potential source of food contamination for the population.

\section{Conflict of Interest}

No conflict of interest associated with this work. 


\section{Acknowledgements}

The authors thank Ankara University Scientific Research Projects Coordination Unit (Project number 15B0443010) for financial assistance. We also thank Prof. Dr. Mustafa Akçelik (Ankara University) for supplying references strains.

\section{References}

Abay S, Aydın F, Sümerkand AB. 2012. Molecular typing of Listeria spp. isolated from different sources. Ankara Üniv. Vet. Fak. Derg., 59: 183-190.

Abrahao WM, Abrahao PRS, Monteiro CLB, Pontarolo R. 2008. Occurrence of Listeria monocytogenes in cheese and ice cream produced in the State of Prana, Brazil. Braz. J. Pharm. Sci., 44: 289-296.

Al-Mariri A, AbouYounes A, Ramadan L. 2013. Prevalence of Listeria spp. in Raw Milk in Syria. Bulg. J. Vet. Med., 16(2): $112-122$

Anonymus. 2017. NCBI Taxanomy Browser. https:/www.ncbi.nlm.nih.gov/Taxonomy/Browser/wwwtax.cgi ?id=1637 Access Date: (24.03.2017)

Arrese E, Arroyo-Izaga M. 2012. Prevalence of Listeria monocytogenes in Idiazabal cheese. Nutr Hosp., 27(6):21392141. DOI: $10.3305 /$ nh.2012. 27.6.6052.

Arslan S, Özdemir F. 2008. Prevalence and antimicrobial resistance of Listeria spp. In homemade white cheese. Food Control, 19: 360-363. DOI:10.1019/j.foodcont.2007.04. 009.

Aygun O, Pehlivanlar S. 2006. Listeria spp. in the raw milk and dairy products in Antakya, Turkey. Food Control, 17: 676-679. DOI:10.1016/ j.foodcont. 2005.09.014.

Barre L, Angelidis AS, Boussaid D, Brasseur ED, Manso E, Besse NG. 2016. Applicability of the EN ISO 11290-1 standard method for Listeria monocytogenes detection in presence of new Listeria species. Int. J. Food Microbiol., 238:281-287. DOI: 10.1016/j.ijfoodmicr.2016.09.028.

Bouayad L, Hamdi TM. 2012. Prevalence of Listeria spp. In ready to eat foods (RTE) from Algiers (Algeria). Food Control, 23:397-399. DOI: 10.1016 /i.foodcont. 2011. 08. 006.

Demir P, Öksüztepe G. 2016. Şavak Tulum Peynirlerinde Listeria monocytogenes ve Salmonella spp'nin Varlığı. F. Ü. Săg. Bil. Vet. Derg., 30(2): 119-122.

Durmaz H, Avc1 M, Aygün O. 2015. The Presence of Listeria Species in Corn Silage and Raw Milk Produced in Southeast Region of Turkey. Kafkas Univ. Vet. Fak. Derg., 21:41-44. DOI: $10.9775 / \mathrm{kvfd} .2014 .11664$.

Elshinaway SH, Meshref AMS, Zeinhom MMA, Hafez DAA. 2017. Incidence of Listeria Species in Some Dairy Products InbeniSuef Governorate. Assiut. Vet. Med. J., 63: 5-13.

Fox E, Hunt K, O’Brian M, Jordan K. 2011. Listeria monocytogenes in Irish Farmhouse Cheese Environments. Int. J. Food Microbiol., 145: 539-545. DOI:10.1016/ j.ijfoodmicro.2010.10.012.

Garedew L, Taddese A, Biru T, Nigatu S, Kebede, E, Ejo M, Fikru A, Birhanu T. 2015. Prevalence and antimicrobial susceptibility profile of Listeria species from ready-to-eat foods of animal origin in Gondor Town, Ethiopia. BMC Microbiol., 15:100. DOI:10.1186/s12866-015-0434-4.

Gebretsadik S, Kassa T, Alemayehu H, Huruy K, Kebede N. 2011. Isolation and characterization of Listeria monocytogenes and other Listeria species in foods of animal origin in Addis Ababa, Ethiopia. J. Infect. Public Health, 4: 22-29. DOI:10.1016/j.jiph.2010.10.002.

Hellberg RS, Martin KG, Keys AL, Haney CJ, Shen Y, Smiley RD. 2013. 16S rRNA partial gene sequencing for the differentiation and molecular subtyping of Listeria species. Food Microbiol., 36: 231-240. DOI: 10.1016/j.fm.2013.06.001.

ISO 11290:1996 Microbiology of food and animal feding stuffsHorizontal method for the detection and enumeration of Listeria monocytogenes-Part 1: Detection method.
Jamali H, Chai LC, Thong KL. 2013. Detection and Isolation of Listeria spp. And Listeria monocytogenes in ready-to-eat foods with various selective culture media. Food Control. 32:19-24. DOI:10.1016/j.foodcont.2012.11.033.

Jami S, Jamshidi A, Khanzadi S. 2010. The presence of Listeria monocytogenes in raw milk samples in Mashhad, Iran. Iranian J. Vet. Res., 11(4):363-367.

Kaptan B. 2016. Prevalence of Listeria spp. and L. monocytogenes in Homemade Pottery Cheese. Tekirdağ Ziraat Fakültesi Dergisi. 13: 80-87

Korsak D, Szuplewska M. 2016. Characterization on nonpathogenic Listeria species isolated from food and food processing environment. Int. J. Food Microbiol., 238: 274-280. DOI: 10.1016/j.ijfoodmicro.2016.08.032.

Momtaz H, Yadollahi S. 2013. Molecular Characterization of Listeria monocytogenes isolated from fresh sea food samples in Iran. Diagn. Pathol., 8: 149.

Nayak DN, Savalia CV, Kalyani IH, Kumar R, Kshirsagar DP. 2015. Isolation, identification and characterization of Listeria spp. from various animal origin foods. Vet. World, 8: 695-701. DOI:10.14202/vetworld.2015.695-701.

Odetokun IA, Adetunji VO. 2016. Prevalence and persistence of Listeria monocytogenes in dairy and other ready-to-eat food products in Africa. Microbes in Food and Health, 319: 349-361. DOI: 10.1007/978-3-319-25277-3-18.

Phraephaisarn C, Khumthong R, Takahashi H, Ohshima C, Kodama $\mathrm{K}$, Techaruvichit $\mathrm{P}$, Vvesaratchavest $\mathrm{M}$, Taharnklaew $\mathrm{R}$, Keeratipibul S. 2017. A novel biomarker for detection of Listeria species in food processing factory. Food Control, 73: 1032-1038. DOI:10.1016/j.foodcont.2016.10.001.

Rahimi E, Momtaz H, Sharifzadeh A, Behzadnia A, Ashtari MS, Esfahani SZ, Riahi M, Momeni M. 2012. Prevalence and Antimicrobial Resistance of Listeria Species Isolated from Traditional Dairy Products in Chahar Mahal \& Bakhtiyari, Iran. Bulgarian J. Vet. Med., 15: 115-122.

Sağun E, Sancak YC, İşleyici Ö, Ekici K. 2001. Van ve Çevresi Süt ve Otlu Peynirlerinde Listeria Türlerinin Varlığı ve Yaygınlığı Üzerine Bir Araştırma. Turk. J. Vet. Anim. Sci., 25: 15-19.

Saludes M, Troncoso M, Figuero G. 2015. Presence of Listeria monocytogenes in Chilean food matrices. Food Control, 50: 331-335. DOI: 10.1016/j.foodcont.2014.08.008.

Sarker R, Ahmed S. 2015. Prevalence and Antimicrobial Susceptibility of Listeria spp in Dairy Food Products and Water Samples in Dhaka, Bangladesh. J. Life Sci., 9:152-158. DOI:10.17265/1934-7391/2015.04.002.

Seyoum ET, Woldetsadik DA, Mekonen TK, Gezahegn HA, Gebreyes WA. 2015. Prevalence of Listeria monocytogenes in raw bovine milk and milk products from central highlands of Ethiopia. J. Infect Dev. Ctries., 9: 1204-1209. DOI: $10.3855 /$ jidc. 6211 .

Shamloo E, Jalali M, Mirlohi M, Madani, G, Metcalf D, Merasi MR. 2015. Prevalence of Listeria spp. in raw milk and traditional dairy products in Isfahan, Iran. Int. J. Environ. Health Engineering, 4:1.

Silva IMM, Almeida RCC, Alves MAO, Almedia PF. 2003. Occurrence of Listeria spp. in critical control points and the environment of Minas Frescal cheese processing. Int. J. Food. Microbiol., 81:241-248.

Taşçı F, Türütoğlu H, Öğütçü H. 2010. Investigations of Listeria Species in Milk and Silage Produced in Burdur Province. Kafkas Univ. Vet. Fak. Derg., 16:S93-S97. DOI:10.9775/kvfd.2010.1744.

Van Kessel JS, Karns JS, Gorski L, McCluskey BJ, Perdue ML. 2004. Prevalence of Salmonella, Listeria monocytogenes, and fecal coliforms in bulk tank milk on US dairies. J. Dairy Sci., 87: 2822-2830.

Vardar-Ünlü G, Ünlü M, Bakıcı MZ. 1998. Incidence of Listeria spp from raw milk in Sivas. Tr. J. Medical Sci., 28: 389-392.

Yehia HM, Ibraheim SM, Hassanein WA. 2016. Prevalence of Listeria species in some foods and their rapid identification. Trop. J. Pharm. Res., 15: 1047-1052. DOI: 10.4314/ tjpr.v15i5.21. 